\title{
EL CONOCIMIENTO "FORMA" CUANDO SE SABE "DEFORMADO" POR EL SUELO QUE HABITAMOS
}

\author{
Carlos A. Cullen*
}

Recebido: 12 jun. 2014

Aprovado: 31 jul. 2014

* Universidad Nacional de Buenos Aires (UBA) Ciudad Autónoma de Buenos Aires, Argentina. E-mail: cacullen@ciudad.com.ar

Resumen: La tesis que sostiene este trabajo es que la formación es una cultura que busca su sujeto, para lo cual se intenta una breve genealogia del concepto, para delinear luego una presentación narrativa de su sentido hoy. La relación del conocimiento aparece así como resistencia al pensamiento único y a la pretensión de una sola forma de entender el sujeto cognoscente y la verdad.

Palabras claves: Formación (Bildung). Conocimiento. Pensamiento gravitado. Estar-siendo.

\section{THE KNOWLEDGE "FORMS" WHEN IT IS KNOWN "DEFORMED" BY THE SOIL THAT WE LIVE ON}

Abstract : The thesis that supports this work is that educating is a culture that looks for its subject, searching for a brief genealogy of the concept to delineate a narrative presentation of its sense today. The relation of knowledge appears therefore as resistance to a single thought and to the pretension of one single form of understanding the knowing subject and the truth.

Key words: Formation (Bildung). Gravitated knowledge. Be-being .

\section{O CONHECIMENTO "FORMA" QUANDO SE SABE \\ "DEFORMADO" PELO CHÃO EM QUE VIVEMOS}

Resumo: A tese que sustenta este trabalho é que a formação é uma cultura que busca seu sujeito, iniciando com uma breve genealogia do conceito, para em seguida delinear uma apresentação narrativa de seu sentido atual. A relação do conhecimento aparece assim como resistência ao pensamento único e à pretensão de uma única forma de entender o sujeito cognoscente e a verdade.

Palavras-chave: Formação (Bildung). Conhecimento. Pensamento gravitado. Estar-sendo. 
Se trata en esta conferencia de discutir las relaciones entre "formación y conocimiento", tal como lo propone este Congreso, para lo cual mi propuesta, a manera de tesis, es la siguiente:

La formación consiste en una cultura que busca su sujeto, y por lo mismo el conocimiento "forma", cuando se sabe "deformado" por el suelo que habitamos. Dicho de otro modo: el sujeto de conocimiento (el cogito) es el resultado más el proceso de esa búsqueda, en que consiste la cultura, $\mathrm{y}$, por lo mismo, queda siempre referido y diferido por el "estar, meramente estar", que busca, al "formarse" un modo de "estar-siendo", acertar un sentido, para remediar "el hambre originario que va desde el pan hasta la divinidad", que define la necesidad de cultivarse. El sujeto de conocimiento es entonces un estar-siendo-así, y no un pretendido lugar a-histórico y desgravitado ${ }^{1}$.

Estructuramos el trabajo discutiendo primero la idea misma de formación, para lo cual intentaremos dos caminos: el de una "genealogía" del concepto y el de una "presentación narrativa de su identidad". En segundo lugar discutiremos el lugar del conocimiento como pensamiento crítico en el proceso mismo de formación, para terminar, finalmente, con algunas consideraciones sobre el sentido ético político de entender de esta manera la relación de la formación, que es la cultura y la educación, con el conocimiento.

\section{EN TORNO A LO QUE ENTENDEMOS POR FORMACIÓN}

\subsection{Breve "genealogía" del concepto de "formación"2}

Puede ser fecundo, a los efectos de este trabajo, intentar una "genealogía" (en el sentido nietzscheano y foucaultiano ${ }^{3}$ ), para luego en el apartado siguiente, intentar presentar narrativamente su identidad como problema, sabiendo de su rica "polisemia", sobre todo cuando traduce el concepto alemán de Bildung ${ }^{4}$.

Hay una primera concepción de la "formación" que podemos englobarla en una categoría amplia como la de "naturalismo", que -paradójicamente- tiene una cara "metafísica de la sustancia" y otra "metafísica del sujeto", e incluso una tercera que niega estas especulaciones y se define como "positivista".

1 Interpretamos así ideas expuestas ampliamente por Rodolfo Kusch que a lo largo de su extensa obra (hoy reunida su Obras Completas en cuatro tomos por la Editorial Fundación Ross de Rosario Argentina 1998-2003) insiste en la fecundidad filosófica que encierra la oposición ser y estar, precisamente para repensar la cultura (y la formación) y su relación con un conocimiento que no de la espalda, ilusoria (o colonialmente) a lo que llama en sus trabajos la América Profunda, o simplemente lo profundo de cada cultura, que justamente busca su sujeto. Cfr. Cullen(2010a).

2 Varias de las ideas de este apartado las hemos trabajado en otros lugares. Cfr. Cullen $(2007,2004)$

3 En particular la distinción nietzscheana, que "explota" Foucault, entre "origen " (Ursprung) con "procedencia" (Herkunft) y emergencia (Entstehung). Cfr. Nietzsche (1980) y Foucault (1992).

4 Esto es especialmente trabajado por Rajmanovich(2012), donde discute las interpretaciones de Buck y de Liedman. 
La diferencia, ciertamente enorme, radica en que el concepto de fundamento tenga que ver con la idea de un origen dado (en este sentido natural) y siempre igual a sí mismo:

Sea: como idea arquetípica o esencia inteligible, como subjetividad trascendental (centro descentrado) o espíritu absoluto (esfera de las esferas), o bien como una idea de un origen como dato inmediato "neutro" (fuerzas y/o talentos naturales simplemente observables y descriptibles).

En los dos primeros casos la formación se entiende como desarrollo natural, como un movimiento "endógeno", justamente de las facultades que se desprenden de la esencia misma o de la subjetividad a priori, o simplemente de los "dotes" naturales. En el debate actual estas ideas están siendo re-significadas por el concepto de "educabilidad", con sus fáciles deslizamientos a una ideología segmentadora o abiertamente excluyente (CULLEN, 2010b).

Se trata del paso de la potencia (forma esencial) al acto, o de las condiciones de posibilidad a su realización (de la competencia a priori a la performance), de lo que cada uno puede a lo que efectivamente hace.

En realidad siempre, en estos casos, aparecen juegos de poder entre el lugar de la luz y el de las sombras, el "maestro" y el "discípulo", o el "uso público" y el "privado", todas formas de esconder la disimetría de poder entre "el camino de alguno y de los muchos", entre "el asceta contemplativo" y los "hedonistas", entre "los que se atreven a pensar y los que culpablemente prefieren tutores". Distinción que se reitera aun en la deconstrucción de la fundamentación metafísica, ahora: entre "los hombre superiores y el rebaño" entre "los auténticos y los que se pierden el anonimato del se dice, se hace", en definitiva: "entre la élite formadora que disciplina y el pueblo caótico que tiene que ser disciplinado".

En el caso del "positivismo" la formación se entiende como in-formación exógena, porque la "forma" está dada inmediatamente en la realidad y se trata de aprender a recibirla sin prejuicios, dejándose in-formar por la realidad misma , aprendiendo las reglas del "método" para saber adaptarse 5 .

Esta tensión entre el desarrollo endógeno de la forma dada en el individuo, tanto como forma de la materia, en el compuesto sustancial de la antiguedad, o como forma legisladora de lo dado externamente, en el individuo libre e igual de la modernidad ilustrada, es pensada, en la concepción romántica de la Bildung, particularmente en Hegel, como una contradicción dialéc-

5 Hay una alusión al pensamiento de Durkheim, que sin embargo, exigiría matices que escapan a este trabajo. 
tica, porque el problema es el paso de la sustancia al sujeto, donde el en-si se sabe para-sí, y el para-sí se sabe realidad efectiva ${ }^{6}$.

Es decir el concepto de formación en este "origen" romántico se sabe tanto desarrollo del individuo como progreso de la humanidad, es decir, toma un carácter socio-histórico, y ya no meramente "desarrollo natural", aún cuando la modernidad suponga una armonía preestablecida, o bien confíe utópicamente que la educación, a la larga, armonizará la libertad con la naturaleza.

La formación (Bildung) considerada bajo este aspecto y desde el punto de vista del individuo, consiste en que adquiere lo existente y consuma y se apropia su naturaleza inorgánica. Pero esto, visto bajo el ángulo del espíritu universal como la sustancia significa sencillamente que esta se da su autoconciencia y producir dentro de sí misma su devenir y su reflexión (HEGEL, 1994, p. 22).

En el mismo registro dialéctico fue particularmente significativa la corrección (inversión) que el materialismo histórico intentó, al señalar que tanto la formación del individuo como la formación del "espíritu universal" están determinadas por las condiciones materiales de la relaciones de producción que se han ido generando a lo largo de la historia, por lo cual en el proceso de formación hay que distinguir entre "alienación" y "emancipación", lo cual sugiere elementos para una "crítica a la filosofía de la Bildung", por lo que puede tener de ideológico o justificador, como conciencia falsa o ideología, de la explotación del hombre por el hombre.

Es sabido que en la historia del Marxismo fue Gramsci quien más insistió en el rol de la educación y de la cultura en esta "lucha por la hegemonía", como forma de crítica a la ideología (GADOTTI et al., 2011).

Lo que nos interesa rescatar en esta breve genealogía del concepto de formación es la relación del saber con el poder, entendido como "dominio", como insistentemente lo ha remarcado M.Foucault, disciplinando toda forma alternativa a la hegemónica, que es, entonces "anormal" y necesita ser vigilada y castigada, tesis que amplió para profundizar en la relación libertad y poder, donde se define la "gubenamentalidad" (CASTRO GOMEZ, 2010).

\subsection{Presentación Narrativa de la Identidad Hoy de la Formación}

\section{a) La formación como praxis}

La formación es tematizada, en una primera escena, como "praxis", en ese decisivo sentido que le dio ya Aristóteles, al distinguirla del mero movimiento

6 Además de la referencia a Hegel hay que mencionar a Herder, Humbodt, Schiller y el mismo Gooethe 
natural, desde dos argumentos: la praxis supone un fin intencional (se sabe lo que se va actuar) y un sujeto "voluntario" (libre) que podría, entonces, no actuar o actuar de otra manera. Es decir, la praxis es "contingente", y, en este sentido primero la formación exige deliberación con razones y elección del justo medio, la "buena" formación, para no pecar ni por exceso ni por defecto. Se inaugura así un campo problemático para teorizar sobre la formación, porque se trata de algo "contingente".

Sin embargo, en este primera escena, que se prolonga hasta finales del siglo XVIII, podemos contar, para buscar la formación buena, con el recurso que nos da la naturaleza, ya que el hombre es el único viviente que tiene "logos", o, como se expresará muchos siglos después Kant, por algo la naturaleza nos dio razón práctica.

Y esto permitirá distinguir, por un lado, una formación específica según el ideal de vida buena elegido (el "hedonista", el "activo", el "contemplativo", o como los lee H.Arednt: "la labor", el "trabajo", la "acción"), elección fuertemente determinada por jerarquías "naturales", pues no es lo mismo formar niños y mujeres, trabajadores y comerciantes, políticos y pensadores (siempre varones y mayores de 18 años y libres). La praxis formativa (y educativa: la paideia, en definitiva) aparece así como segmentada jerárquicamente por naturaleza.

Y, por otro lado, ya en terreno "moderno", se podrá distinguir una formación específica para quienes hacen un uso "público" de la razón: los doctos, y para quienes tienen que limitarse a un uso "privado" de la misma razón práctica: los que tienen que actuar normados por funciones institucionales destinadas a mantener el orden social: los funcionarios o profesionales que ejercen cargos regulados o bien los que no se atreven a hacer un uso público de la razón y necesitan, como los niños, "crianza" y "disciplina": simplemente el pueblo, que se supone no ilustrado y se opone a los doctos. Dice Kant en su Pedagogía de 1803 (2014, p. 8):

La Pedagogía o teoría de la educación es o física o práctica. La educación física es aquella que el hombre tiene de común con los animales, o sea los cuidados. La educación práctica o moral es aquélla mediante la cual el hombre debe ser formado para poder vivir, como un ser que obra libremente--. Así, pues, esta educación se compone: a) de la formación escolástico-mecánica, que se refiere a la habilidad; entonces es didáctica (instructor); b) de la formación pragmática, que se refiere a la prudencia (ayo); c) de la formación moral, que se refiere a la moralidad ${ }^{7}$.

7 El texto está tomado de las lecciones sobre Pedagogía que Kant dictó en la Universidad de Königsberg, y que fue publicado, con su autorización, en 1803. Con el título Pedagogía la editorial Akal, de Madrid, 
Esta manera de entender la formación supone una subjetividad dada, pero en potencia o acto, o bien una subjetividad educable en esos momentos distinguidos por Kant, en el texto citado.

Y viene, justamente el momento de "suturar" narrativamente la diferencia puramente "negativa" de sustancia y sujeto, de realidad y racionalidad. Es decir, el más que decisivo viraje en la concepción de la Bildung que produce el Romanticismo sobre todo con Herder, Humboldt Schiller y Hegel.

Se trata de entender la "formación" como ciencia de la experiencia de la conciencia, subtítulo que puso Hegel en 1807 a la Fenomenología del Espíritu. Las claves de esta visión dialéctica de la Bildung o formación como praxis está, por un lado, en entender que el sujeto formado como "razón" es resultado de un proceso más el mismo proceso, que va de la teoría mediando la práctica a la racionalidad, $y$, por otro lado, que esta racionalidad tiene un proceso de formación "sustancial", que va desde una eticidad inmediata, mediando el extrañamiento socio-histórico en las relaciones de poder, riqueza y saber (que es lo que justamente Hegel llama Bildung) a un retorno a la certeza mediada por todo este proceso del espíritu moral.

Es decir, la formación es ya una praxis determinada por un proceso socio-histórico, y no meramente por el uso prudente de la facultad de pensar o el buen uso de la razón metódicamente disciplinada, como diría Descartes, y dentro de sus límites, como diría Kant. El enfoque de Marx, como ya lo insinuamos, crítica el planteo de la "formación" como mero devenir de la idea en naturaleza y espíritu, y acentúa el carácter material, el devenir de las fuerzas productivas y las relaciones de producción, como los determinantes del proceso.

Tratando de superar lo que aparece como una visión estrechamente monológica de la Bildung como praxis y con fuerte influencia del "giro linguístico que se produce en el pensamiento a partir de la segunda mitad del siglo XIX, J.Habermas, recogiendo la crítica a la razón instrumental de sus colegas de Frankfurt Adorno y Horckheimer. intenta avanzar en la idea de la Bildung como praxis insistiendo en la idea de una "acción comunicativa", que sin abandonar un fundamento cuasi-trascendental (la competencia comunicativa), abre claramente para la formación la relación intersubjetiva, mediada, justamente, por la normatividad de reglas del diálogo, desde el supuesto de una comunidad ideal de hablantes. No se trata ya meramente de la autonomía como "juicio moral" sino de la autonomía como lucha por el reconocimiento que busca consensos en las reglas o normas que regirán la acción de los interesados.

publicó estas lecciones y otros escritos "pedagógicos” de Kant. Usamos la versión en pdf. de la Escuela de Filosofía Arcis 
Sin duda que el entender la praxis de la Bildung como acción comunicativa, y no meramente como acción instrumental (de extrañamiento y apropiación) es un paso adelante en la significación de la formación, porque pone en juego el tema de la participación de los interesados, tema que la pedagogía dialógica, con Freire a la cabeza, ponen en el centro de todo proceso educativo $\mathrm{y}$ formativo.

Pero acá también aparece en escena un matiz de particular importancia: es que la formación no sólo debe ser una praxis comunicativa y dialógica sino que es necesario agregar que debe ser liberadora, entre otras razones, porque no se da habitualmente una situación ideal de simetría de los hablantes, y es necesario, entonces, explicitar la situación real de opresión y de exclusión de buena parte de la humanidad involucrada en los procesos de formación. No alcanza, en mi opinión, poner un interés emancipatorio el conocimiento, marcado por los ideales supremos de la razón, precisamente porque esa razón sigue pretendiendo saberse desgravitada, y entonces, siempre igual a sí misma, universal y necesaria, es, por lo mismo, deudora de lo que llama W. Mignolo (2011) la "cara oculta de la modernidad: la colonialidad", que se anima a proclamar, cuando no se quiere o no se sabe dialogar, el derecho a ejercer un "paternalismo responsable. ${ }^{8}$

Opuesto a esto Paulo Freire insiste en una "Pedagogía del Oprimido" (1990) y una "Pedagogía de la autonomía" (1999), retomando la idea de una "Educación como Práctica de la Libertad" (1969). Màs explícitamente, todavía, E. Dussel (1980) viene trabajando en su monumental Ética de la Liberación en una "Pedagógica de la liberación", partiendo de lo que llama la "comunidad de las víctimas", y no de una supuesta razón arquetípica o trascendental.

\section{b) La formación como experiencia y cuidado de sí}

A finales del siglo XIX y a lo largo del XX, y en nuestros días, se abre otra escena en esta presentación narrativa de la "formación", justamente la que intenta una "genealogía" del concepto, afirmando con énfasis que "lo mismo no es lo igual", y por lo mismo es necesario reiterar la pregunta por el fundamento, en nuestro caso de la formación, porque, como lo afirma Heidegger, "la ontología precede a la metafísica".

Nos parece particularmente significativo seleccionar, a los efectos de esta presentación, los aportes de Foucault y de Agamben, ciertamente influidos por el giro deconstruccionista, iniciado por Nietzsche y Heidegger.

8 Cfr. De la obra de Habermas (1990, 1997, 1998). De Mignolo (2011). 
De aquí el paso que damos: la formación es praxis (comunicativa y liberadora), pero es también experiencia en el sentido estricto que le da Giorgio Agamben (2007, p. 7), cuando diagnostica "que al hombre contemporáneo se le ha expropiado su experiencia", y por lo mismo, la posibilidad de distinguir lengua y habla. Es lo que llama la "infancia" como "experiencia trascendental de la diferencia entre lengua y habla, que abre por primera vez a la historia un espacio". Sin infancia no hay historia, dice Agamben, y nosotros glosamos el texto diciendo sin infancia, sin experiencia, no hay formación de un sujeto del lenguaje y de la historia.

Sin duda que esto habla de la necesaria historicidad presente en la "formación", sin tener que apelar a modelos arquetípicos o a-históricos, para llegar a ser sujeto que habla y piensa bien. Justamente acá se junta este motivo reflexivo en torno a "infancia y experiencia" con las preocupaciones de Foucault de entender la "formación" como cuidado de sí, es decir, resistencia a la des-subjetivación, o a la privación de experiencia.

Aceptar que la formación además de "praxis" es "experiencia" o "cuidado de sí" implica no entender la forma ni como idea o esencia arquetípica, ni como subjetividad a priori. Se trata de modelos históricos, donde hay que dejar jugar a la verdad como relaciones o juegos de poder, y no pretender que el formado simplemente se modele conforme a un prototipo de sujeto "bien formado" o "culto" o simplemente "bien educado", suponiendo una forma canónica de entender la verdad. Se trata, entonces, de una "hermenéutica del sujeto", que para la relación de formación pone en juego la "parresía", es decir, la franqueza (FOUCAULT, 1994, p. 98-99):

Parresía etimológicamente significa decirlo todo. La parresía lo dice todo; no obstante, no significa exactamente decirlo todo, sino la franqueza, la libertad, la apertura que hacen que se diga lo que hay que decir, como se quiere decir, cuando se quiere decir y bajo la forma que se considera necesaria.

Para nuestro planteo esto se traduce en la presencia de la diferencia en todo planteo educativo o formativo, sabiendo que lo mismo no es lo igual, que en lo dicho hay siempre algo no dicho, o, como se expresa J. Derrida (1995, p. 13), que en la presencia hay ausencias, "fantasmas de las víctimas de todas las injusticias imaginables, que desquician nuestro presente vivo".

Que la formación es experiencia significa entonces que en ella se abre lo "nuevo", la "diferencia", lo que desnaturaliza lo humano y entonces, lo forma históricamente como humano. 


\section{c) La formación como responsabilidad y cuidado del otro en cuanto otro}

Recién en las segunda mitad del siglo XX explicitamos la necesidad de resignificar la identidad narrativa de la "formación", ante un olvido más grave que las máscaras o simulaciones nietzsheanas o el olvido del ser heideggeriano: es el sentirse "invulnerables" ante la exterioridad del otro en cuanto otro. Porque además de ser praxis-comunicativa-liberadora y experiencia-cuidado de sí, la formación es responsabilidad y cuidado del otro en cuanto otro. Lo cual pone en escena no sólo la precedencia de la ontología en relación a la metafísica, el acontecer en relación a lo siempre igual a sí mismo, la diferencia di-fiiriendo la identidad, sino la precedencia de la ética en relación con la ontología, es decir, la alteridad interpelando a la totalidad, tanto de la "identidad" como la de la "diferencia", entendida como los bordes de lo mismo tal como lo plantea E. Levinas $(1977,1987)$.

La formación es capacidad de dar respuesta a la interpelación ética del otro en cuanto otro es decir, comienza siempre por ser hospitalidad, acogida del rostro del otro que interpela éticamente diciendo: "heme aquí, no me violentes". En este sentido, anterior a toda anterioridad, la iniciativa, en la formación, la tiene el otro en cuanto otro, y es esa alteridad, exterior a toda totalidad (real o simbólica), que en la relación "se absuelve de la relación", el verdadero maestro que forma y posibilita que se de praxis, comunicativa y liberadora, experiencia y cuidado de sí, porque es esta interpelación la que libera a la libertad misma, al sacarla de su ilusoria espontaneidad sin límites y la convierte en hospitalidad.

Desde siempre somos "guardianes de nuestros hermanos", es decir responsables, lo cual pone como fundamento sin-fundamento (an-árquico, diría Levinas) de la formación, precisamente el sabernos "vulnerables", es decir, siempre interpelables por el rostro del otro en cuanto otro, capaces de entender la formación como una relación que en la relación se absuelve de la relación

Ningún momento ni modo de la formación, entonces, puede justificar cualquier tipo de violencia a la alteridad. En este sentido, en la formación como praxis, como experiencia y cuidado de sí siempre se pone en juego el cuidado del otro en cuanto otro es decir, simplemente, la justicia.

\section{d) La formación siempre gravitada y buscando su sujeto}

Junto a la ética en el sentido explicitado, hay algo más que precede a la ontología, y es también un momento del relato que nos permite definir "nar- 
rativamente" la identidad de la formación. Es el estar que precede al ser, el margen de arraigo en el suelo que se habita, justamente como "instalación" en el estar, meramente estar, que es lo profundo sin nombre y sin dueño, porque es la "tierra de nadie" y por lo mismo, la de todos, y que se da como el "hambre o indigencia originaria que va desde el pan hasta la divinidad", y entonces la formación va aconteciendo como un "remedio" a esta indigencia, pero siempre como un "acierto" fundante de sentido, que permite "adjetivar" el ser, y entender la "forma" encontrada "lúdicamente" (es decir no como certeza necesaria) como un estar-siendo, y no pretende comprender la formación como lograr un ser sin estar, como si pudiéramos conjurar la presión del estar y sacarnos el "lastre" de encima.

Precisamente de esto se trata en la formación: que desde el estar y la vulnerabilidad pueda cada uno y todos, encontrar el sujeto, es decir, el sujeto que goza, actúa y piensa, el sujeto que se comunica, el sujeto que hace historia cuidando su sí mismo y resistiendo a la exclusión de los "muchos".

Es decir la formación es praxis, experiencia, cuidado de sí y cuidado del otro, cultura que busca su sujeto, su estar-siendo-así, siempre gravitada por el suelo que se habita.

\section{EL LUGAR DEL CONOCIMIENTO EN LA FORMACIÓN COMO PENSAMIENTO CRÍTICO}

Desde la breve "genealogía" esbozada y desde la suscinta presentación de la identidad narrativa del concepto de formación, hagamos ahora algunas consideraciones sobre la relación de la formación con el conocimiento.

Nuestra afirmación básica acá es sostener que el conocimiento que forma es el que aumenta la "potencia de actuar", pero no sólo en el sentido spinociano de ser "causas de lo que sucede", sino, y sobre todo, aprendiendo a sentir las verdades "seminales", esas que brotan y no sabemos por qué, pero donde se pone en juego el "sentido" y no meramente la "utilidad". Es decir, el conocimiento no es sólo un instrumento para movernos en el patio de los objetos, que podemos explicar y usar, sino también lo que nos hace descender al subsuelo de lo profundo del mundo de la vida, no para "ponerlo entre paréntesis" hasta que nuestra subjetividad trascendental intuya lo esencial, sino para dejar que aparezcan las verdades seminales, y, entonces, lúdicamente encontremos "aciertos fundantes de sentido", sin pretender reducirlas a términos intencionales de nuestra conciencia.

9 El concepto de "verdades seminales" es trabajado fuertemente por Kusch en su obra "La negación en el pensamiento popular", ahora en las Obras Completas, ya citada. 
Se trata de poner en juego en la formación un pensamiento crítico. Y acá nos permitimos explicitar qué entendemos por pensamiento crítico, evitando así la vaguedad con que con muchísima frecuencia hablamos de "formar el pensamiento crítico" o de entender la buena formación como la que está atravesada por una concepción crítica del conocimiento forma

En primer lugar, un pensamiento crítico se define como una racionalidad dialéctica, que supone mediar las relaciones de teoría y práctica.

Desde que entendemos la formación y la educación, como praxis, es decir, como acción contingente, libre e intencional, se plantea el problema de qué tipo de conocimiento puede hacerse cargo de fundamentar críticamente una praxis (que no es mero movimiento natural o cosa extensa).

Este problema lo plantea ya Aristóteles en el comienzo de la Ética a Nicómaco, cuando afirma que en estas cuestiones no podemos pretender el mismo tipo de conocimiento que el de los objetos naturales. Reaparece el problema en la modernidad, en Kant claramente, cuando se hace necesario distinguir la ley de la naturaleza y la ley de la libertad. Es decir, como entender una teoría de la práctica que no caiga en un reduccionismo naturalista.

Aristóteles encuentra un aliado por el lado de los fines de la acción, discutiendo entonces cual es el fin último, que está determinado por la naturaleza misma, y de acá se inaugura, hasta nuestros días, el papel del conocimiento para discutir cuáles son los fines de la formación, para encontrar la educación buena, o como se habla en los últimos años, una formación de "calidad". La pregunta por los fines de la formación como praxis, insiste y persiste.

Kant, en cambio, encuentra un aliado por el lado de las leyes o normas o principios que rigen la acción y acá reflexiona que la naturaleza "por algo nos dio" una razón práctica que se rige autónomamente, pues contiene un principio incondicionado para las acciones: el imperativo categórico. Acá aparece la necesidad de avanzar sobre los "fines" de la formación, planteando la cuestión de si son correctos "moralmente", es decir, "justos" o no. Esto inaugura fuertemente la cuestión de los principios éticos que han de regir la formación entendida como praxis, problema que insiste y persiste.

En ambas tradiciones para definir el lugar del conocimiento en la formación, la discusión de los fines "buenos" y la de los principios "correctos" se supone, sin embargo, que tanto el "silogismo práctico" como el "uso práctico de la razón pura", son trabajos de un conocimiento independiente de las prácticas históricas y concretas. Se trata de deliberar sobre sus fines buenos o legislar sobre su corrección moral, aplicando a lo fines o máximas particulares de la formación como praxis argumentos o principios teóricos, para discernir su bondad o su corrección. 
Es la dialéctica, y Hegel en particular, quien se encargará de convertir la tensión en una mediación que, en un nivel "estructural", es la praxis quien niega el carácter meramente contemplativo de la teoría, para finalmente, negando esta negación, constituir una razón legisladora, tanto teórica como práctica. $Y$ en un nivel de "realización efectiva" es la praxis "cultural" como extrañamiento o formación (Bildung), quien negando la inmediatez de una supuesta eticidad, logrará formar un "espíritu cierto de sí mismo", amenazado, sin embargo por el mal radical, por lo cual se refugiará finalmente en el arte, la religión y la filosofía.

La crítica del materialismo histórico al idealismo de esta visión se convierte en una crítica al conocimiento como ideología o conciencia falsa, porque separa la formación del "espíritu" de las concretas formaciones históricas determinadas por las relaciones de producción, o sea: de su base material.

Como ya lo insinuamos al hablar de la formación como praxis fue necesario profundizar en la distinción entre acciones estratégicas o meramente instrumentales, y acciones comunicativas, y entonces mostrar los diferentes intereses de la razón al pensar la formación como mera praxis instrumental o como praxis comunicativa y, sobre todo, como ambas formas que puede tomar la praxis, y por lo mismo la formación, están atravesadas por un interés emancipatorio, ligado a los supremos fines de la razón, que Habermas los identifica con el lema de la Revolución francesa: libertad, igualdad, fraternidad.. Todo esto agrega al lugar del conocimiento en la formación la búsqueda de consensos en las reglas y normas, y la ampliación de la participación de los interesados. Es el problema de discutir el carácter democrático de la formación, que, por supuesto, insiste y persiste.

Todavía es importante agregar el tercer rasgo de la formación como praxis que ya mencionamos: el que sea una praxis liberadora, para lo cual el conocimiento que forma tieneque ponerse en el lugar de las víctimas y entender que el principio que debe regir la formación, y es la crítica necesaria, es el principio liberación, como lo llama E. Dussel (2006).

En segundo lugar, un pensamiento crítico se define comouna racionalidad hermenéutica, que supone interpretar la discursividad en que se expresa la dialéctica entre teoría y práctica. Es decir, el conocimiento formador, que como dialéctico se hace cargo de la dimensión práctica de la formación, tanto en su propia constitución como en su realización histórica, sigue siendo, en definitiva, un "discurso" sobre la práctica, es decir, una "episteme", no inmediata, ciertamente, pero no por estar mediatizada deja de ser discurso, que pretende de alguna manera necesidad y universalidad. 
Aquí el conocimiento asume la tarea de tipificar modelos de formación, elementos que la componen, que en su dispersión forman sistema, buscando justamente criticar los supuestamente "malos" y asumir las que pueden leerse como "buenos" (o, en registro ideológico: progresistas).

El tema en cuestión es que la formación además de praxis (y entonces el conocimiento es teoría o episteme) es experiencia, lo cual implica diferencia, "diseminación de sentidos" y apertura a lo nuevo, "el cuidado de sí" exige resistencia a la clasificación normalista de la formación en cuestión: si responde a la "paideia" griega, al "humanismo renacentista", al "proyecto ilustrado", la "Bildung romántica", etc.

Entonces el conocimiento tiene que asumir la tarea crítica como hermenéutica, buscando en qué comunidad de interpretación de basa el modelo de formación propuesto, si es capaz de abrirse a lo nuevo y a lo diferente, si puede hacerse cargo del conflicto de interpretaciones, si es capaz de descongelar supuestas naturalizaciones de las formas de entender la formación.

El conocimiento formador necesita estar abierto a lo nuevo que acontece, ya que la formación es experiencia y no sólo praxis como paso de la potencia al acto.

En esta lectura hermenéutica es necesario discutir las tradiciones históricas que operan sobre la idea de formación y el lugar del conocimiento. Incluso es necesario poner en cuestión el rol jerárquico de algunas disciplinas o conocimientos que suponemos juegan en una buena formación. Se trata de las relaciones del saber con el poder, del saber con el no saber de lo dicho con lo no dicho, de lo presente con lo ausente, de la palabra con el silencio, de lo determinable con lo expresivo el conocimiento formador tiene que ser crítico también en este sentido, para poder hacerse cargo de lo nuevo de la formación como "experiencia", abriendo sentidos simultáneamente desde la memoria (que deja de ser nostalgia) y desde la utopía (que de ser progreso ineluctable de acuerdo a leyes fijas).

¿Nos animamos a ver desde qué comunidad de interpretación leemos el sentido de la formación? Esto es lo que insiste y persiste cuando nos plantamos la relación de la formación con el conocimiento, sabiendo que no es sólo praxis, sino también experiencia.

En tercer lugar, un pensamiento crítico se define como una racionalidad ético-política, que supone interpelar las comunidades interpretativas que se constituyen históricamente en la hermenéutica de la discursividad, incluyendo la dialéctica misma en tanto "teoría" mediada por la praxis.

Es que la formación es, además de praxis y experiencia, responsabilidad, y esto implica que se pone en juego una relación que no es primariamente 
cognitiva, y que, a la inversa, califica al conocimiento formador como siempre "vulnerable" ante la interpelación ética del otro en cuanto otro. Se trata de lo que hemos llamado "obstáculos éticos" en la investigación educativa, que juegan siempre en la relación del conocimiento con la formación, precisamente porque esta es siempre "responsabilidad", cuidado del otro en cuanto otro, y por lo mismo rechazo de todo tipo de violencia o reducción de la alteridad a la mismidad. Y vaya que este tema insiste y persiste (CULLEN, 2010b).

Se trata de tres gestos racionales distintos, con su propia lógica e, incluso, como diría Habermas, con sus propios intereses de conocimiento, pero que siempre están gravitados por el suelo que habitamos.

Mediación, interpretación, interpelación y margen de arraigo. Creo que la racionalidad capaz de sostener una formación como praxis, experiencia y cuidado del otro se constituye como pensamiento crítico, desde estos tópicos o puntos de vista del conocimiento, pero planteados como constituyendo una totalidad sui generis, siempre gravitada por el suelo que se habita. Si "objetivamente" podemos hablar de "prácticas formativas o pedagógicas", como problema epistemólogico proponemos hace ya tiempo hablar de "Crítica de las razones de educar"10.

El conocimiento se relaciona críticamente con la formación si entiende

i) Que se mueve entre "intereses supuestamente trascendentales", "juegos de poder" y "lastres marcadamente político-culturales"

ii) Que la memoria romántica de la "Bildung" corrige la descontextualización ilustrada del "Conocimiento" y desafía un presente sin memoria

iii) El "hedor" de América, como memoria de lo excluido y reprimido, el rostro de las "víctimas", critica el corporativismo acrítico de los críticos: porque es lo previo a las formas ideológicas y a las formas de gubernamentabilidad: se trata simplemente del "estar, no más", es decir, siempre interpelados por el rostro del otro en cuanto otro.

El conocimiento, en las tres vertientes distinguidas, dialéctica, hermenéutica y ética, es resultado del proceso más el proceso mismo de formación cuando desde el mero estar, se busca el sujeto.

10 Con ese nombre hemos publicado un libro, editado en Buenos Aires por Paidós en 1997. Por otro lado Hemos trabajado estas ideas en nuestro conferencia: Resistir e insistir con inteligencia crítica. Tareas y sentidos de la Filosofía de la educación en América Latina, presentado en la reunión anual de la ANPED, acá en Brasil, en el 2005 y luego publicado en nuestro libro Resistir con Inteligencia. Reflexiones éticas sobre educación, publicado en México por la Editorial Pueblo Nuevo y la Casa de la Cultura del Maestro mexicano en el año 2007. Muchas de estas ideas retoman mi artículo Racionalidad y Educación.Racionalidad y Educación. Problemas teóricos y epistemológicos de la educación, en Cullen (2004). 


\section{A MANERA DE CONCLUSIÓN: LA RELACIÓN DE LA FORMACIÓN Y EL CONOCIMIENTO COMO RESISTENCIA Y CREATIVIDAD}

La formación, entonces como la búsqueda del ser sujeto desde el mero estar, y no como la imposición de un modelo único de sujeto para aprender a ser sin estar

Esto permite resistir con inteligencia responsable a un supuesto pensamiento único que pretende separar el sujeto que "formado" piensa y actúa bien, del sujeto cultural que meramente está buscando, justamente, su sujeto.

Pero permite también resistir al miedo de no animarse a buscar una forma de ser sujeto que actúa y piensa bien, y entonces quedarse "anclado" en un sujeto cultural que no busca su sujeto (o que no se lo dejan buscar). Es decir, ni etnocentrismo ni fundamentalismo cultural. Es decir: resistencia y creatividad. "Si sabemos estar, dice R. Kusch, podemos crear el mundo de vuelta".

Entre nosotros es clara, entonces, la relación con la idea de colonialidad, que atraviesa el saber, la autoridad, la institucionalidad (QUIJANO, 2007), porque desde su "seguro" conocimiento formador "puro" y "pulcro" quita el peso o lastre y el "hedor", que viene de lo profundo del suelo que habitamos, y desde esta formación, guiada por esta racionalidad eficiente, segura y pulcra, promete el ingreso a la linealidad progresiva de una historia, que pretende, porque escrita desde una supuesta "astucia de la razón" simplemente, no aceptar el rostro del otro en cuanto otro que interpela éticamente. La formación no es una odisea, para convertirnos en Ulises y aprender la astucia para no ser "rehenes" de la exterioridad, de la alteridad que nos interpela, y, que compartamos la "nostalgia" del retorno a lo mismo, en cada paso que demos.

La formación entonces se relaciona con el conocimiento pero no como una danza ritual "para trenzar y destrenzar cintas en un cuerpo ajeno", sino para perder el miedo a pensar estando, que es lo mismo que operar pensando, porque la cultura (o formación) es gestión, y entonces crear el mundo de vuelta. Y así el conocimiento es "potencia de formación" en tanto potencia de actuar pensando.

De aquí el dilema ético-político en la relación formación y conocimiento:

- O la formación puede esconder una forma de violencia, si no resiste a un pensamiento único, que pretender "formar" desde un conocimiento que entiende la crítica sin el peso del "estar" y con la ilusión de reducir toda alteridad a la mismidad; 
- O la formación manifiesta formas diversas de buscar el sujeto que piensa (el cogito) desde el estar, esa "tierra de nadie" que, por lo mismo es la de todos, y entonces el conocimiento, que "no se ve ni se toca, pero pesa", se sabe en clave intercultural, porque simplemente manifiesta formas de "estar-siendo", sin pretender "ser sin estar" y por lo mismo se sabe siempre vulnerable a la interpelación ética del otro en cuanto otro.

Es decir, el conocimiento que pone en juego y es buscado en la formación es un diálogo real, porque el punto de partida es una simetría "existencial", el estar, meramente estar, y no una supuesta simetría "trascendental" (lo que llama Habermas: situación ideal del habla), que siempre esconde el ser depositaria de las únicas reglas del diálogo posible, sin poner en juego una comprensión traductora.

De aquí el título de esta conferencia: el conocimiento "forma" cuando se sabe "deformado" por el suelo que habitamos, y desde ahi mediatiza la teoría con la práctica, interpreta las tradiciones discursivas sobre la formación y, sobre todo, se sabe siempre interpelado éticamente por el rostro del otro en cuanto otro.

Aceptemos el riesgo o la apuesta de entender la "formación" como praxis, experiencia y responsabilidad, con todos los desafíos para el conocimiento que esto conlleva.

\section{REFERENCIAS}

AGAMBEN, G. Infancia e historia. Destrucción de la experiencia y origen de la historia. Buenos Aires: Adriana Hidalgo, 2007.

CASTRO GOMEZ, S. Historia de la gubernamentalidad. Razón de estado, liberalismo y neoliberalismo en Michel Foucault. Bogotá: Siglo del hombre-PUJ, 2010.

CULLEN, Carlos. Racionalidad y educación. Problemas teóricos y epistemológicos de la educación. En: . (Comp.). Filosofía, cultura y racionalidad crítica. Nuevos caminos para pensar la educación. Buenos Aires: Stella; La Crujía, 2004. p. 17-45. - ¿Patriotas o cosmopolitas? Los dilemas de la subjetividad ciudadana. Metapolítica, México, v. 11, n. 53, p. 50-56, 2007. 
La América profunda busca su sujeto. De cómo entiende Rodolfo Kusch la filosofía Rodolfo Kusch. Espacios de crítica y producción, Buenos Aires, n. 43, p. 88-97, 2010a.

.Entrañas éticas de la identidad docente. Buenos Aires: La Crujía, 2010 b.

DERRIDA, J. Espectros de Marx. Madrid:Trotta, 1995.

DUSSEL, E. La pedagógica latinoamericana. Bogotá: Nueva América, 1980.

DUSSEL, E. Ética de la liberación en la edad de la globalización y de la exclusión. Madrid: Trotta, 2006.

FREIRE, P. La educación como práctica de la libertad. Montevideo: Tierra Nueva, 1969.

. Pedagogía de la autonomía. 3 ed. México: Siglo XXI, 1999.

. Pedagogía del oprimido. Buenos Aires: Siglo XXI, 2002.

FOUCAULT, M.Nietzsche, la genealogía, la historia, en microfísica del poder. Madrid: La Piqueta, 1992.

. Hermenèutica del sujeto. Madrid: La piqueta, 1994.

GADOTTI, Moacir et al. Gramsci y la educación: pedagogía de la praxisyplíticas culturales en América Latina. Buenos Aires: Noveduc, 2011.

HABERMAS, J. Conocimiento e interés. Madrid: Taurus, 1990.

. Teoría de la acción comunicativa. Madrid: Taurus, 1997

. Facticidad y validez. Madrid:Trotta, 1998.

HEGEL, F. Fenomenología del espíritu. México: FCE, 1994.

KANT, E. Escuela de Filosofía Universidad ARCIS. Disponible en:

$<$ www.philosophia.cl/biblioteca/Kant/Pedagogia.pdf $>$. Acceso en: 20 jun. 2014.

LEVINAS, E. Totalidad e infinito. Ensayo sobre la exterioridad. Salamanca: Sígueme, 1977.

. De otro modo que ser o más allá de la esencia. Salamanca:

Sigueme, 1987. 
MIGNOLO, W.The darker side of western modernity.Global futures,decolonial options. Duke: University Press, 2011.

NIETZSCHE, F. Menschliches, allzumenschliches. En: WERKE, I. Ullsteinmaterialien. Frankfurt: Wien, 1980.

QUIJANO, Aníbal. Coloniality and Modernity/Rationality. Cultural Studies, London, v. 21, n. 2-3, p. 155-167, 2007.

RAJMANOVICH, J. Disputas polisémicas en torno a la noción clásica de ‘bildung'. Boletín Virtual REDIPE, Colombia, n. 807, feb. 2012. 